\title{
FTMCP: FUZZY BASED TEST METRICS FOR Cosmetology PARADigm
}

\author{
Shahzad Ashraf ${ }^{1}$, SehrishSaleem ${ }^{2}$ and Syed Afnan ${ }^{3}$ \\ ${ }^{1}$ HohaiUniversity Changzhou Jiangsu, China \\ ${ }^{2}$ Muhammad Nawaz Sharif University of Engineering \& Technology Multan Pakistan \\ ${ }^{3}$ Hilal Foods Private Limited
}

\begin{abstract}
With the advent of modern technology, its essential to avail the latest consumer trends to get maximum efficient results in the context of a globalized market. More attention is paid to the consumption of manufactured goods and everyday items. Much less attention is paid to the service sector, in particular medical, recreational and physical. There is also a lack of application of mathematically grounded, computer methods and models for such modelling. We proposeda fuzzy based test metrics for a cosmetology paradigm (FTMCP) as tasks of multi-criteria decision making on a variety of alternatives. The Specific features of cosmetology services, marketing, communication components are determined. A computer model in the Fuzzy Tech, specialized software product for computer fuzzy modelling, was developed. Integrated assessments for cosmetic institutions have been calculated. The results are analyzed and recommendations for improving the quality of cosmetology service, websites of cosmetology institutions, are suggested. The principles of the proposed approach, the described fuzzy model and its computer implementation can be applied to a wide range of tasks of multi criteria assessment of customer service in various social fields - retail stores, medicine, culture, health, physical education and training, public catering, other household and domestic services.
\end{abstract}

\section{KEYWORDS}

Fuzzy based metrics, paradigm, cosmetology, assessment

\section{INTRODUCTION}

With the passage of time, the competitiveness in service sector in Asian countries is increasing day by day particularly in healthcare sector (cosmetology).There fore, the issues of patients' interaction with healthcare institutions become very relevant. At present, the providers of various treatment services the existence and operation of such institutions of various forms of ownership has createdbroad opportunities for customers to choose the appropriate care and a specific doctor [1]. A visitor to the healthcare centre should choose a specific cosmetology institution, where he/ she will apply, in a variety of proposals with several criteria for quality, safety, price, an assortment of cosmetology services, other service parameters. That is, he/ she faces a question of a multi criteria choice, for the solution of which it is expedient to apply appropriate scientific and practical approaches and methods [2]. On the other hand, the cosmetic institutions themselves, their managers,

DOI: $10.5121 /$ acii.2020.7401 
Advanced Computational Intelligence: An International Journal, Vol.7, No.1/2/3/4, October 2020

marketers, other leading specialists need reliable, scientifically sound, tools (that are not too difficult in practical daily use) for monitoring the quality of their work, and self-evaluation from the perspective of potential customers. It is necessary not only to evaluate themselves but also actual or potential competitors. Therefore, there is an urgent need to develop and use appropriate, modern methods and models.

The consumer behaviour is huge and complex in nature, especially in consumer service decisions[3]. Whether it is affected by buyer's characteristics or the environment of the customers that resulted in an actual purchase. The fact that consumers choose a certain services by a certain firms and disregard others has an important implication [4], to a firm especially the marketing team; it is critical to understand the uniqueness of various consumers, marketers should be able not only producing unique services but also consider their needs, wants and preferences by strategizing the appropriate marketing plan for the firm in order to attract new and existing consumer to avail.

The rest of the findings are structured as: Related work is placed in section 2. The proposed model has been explained in section 3, while concluding remarks are available in section 4 .

\section{RELATED WORK}

The practice shows that while availing variety of services there are numerous unavoidable factor appears very fragmentarily [5]. Despite all, the market for these services is rapidly expanding. Therefore, for the beauty, health, well-being industry, decision-making models are needed by both producers and consumers, taking into account the image, perceived quality, basic marketing components [6]. It presents the results of Six Sigma integration[7], discrete modelling and multicriteria methods for improving beauty services, obtaining compromise solutions about incomes, costs, use of resources and customer satisfaction. The ranking approach in accordance with the preferences of experts was used. The author [8], emphasis the services quality, ways of assessing client's expectations regarding the quality of care in health facilities, the perceived quality of cosmetology services were considered.It is established that positive assessments of the customer service quality are related to the intentions [9], to use it in the future, which ensures a high level of customer retention [10]. If the cosmetic institution supports its clients on a lifelong basis, one can achieve a higher level of client retention and reduce the number of lost customers. Approaches to budget allocation between various components of promotion (and marketing) of cosmetology services were offered [11].

Among the most important areas of research of cosmetology services are the relationships between clients and staff, the corporate loyalty of clients of beauty salons. It is noted that although positive interaction with staff and participation in the development of treatment options is very important, interaction with friends and family and associated activities also have a positive impact on the image of the beauty parlours [12]. Particular attention is paid to the study of the demand for medical cosmetology for Asian countries. It is established that demographic variables and monthly income lead to significant differences in the most desired operation and acceptable costs [13]. It should be noted that the expected improvement in beauty from these services is limited. Despite the attractiveness of the appearance, the economic efficiency of investments in improving the beauty is ambiguous. For the average consumer, the monetary benefits of plastic surgery, cosmetic procedures are sometimes not worth the cost [14]. In connection with discontent with one's own body and manifestations of aging, people resort to various cosmetic therapies, including plastic surgery. Often, 
Advanced Computational Intelligence: An International Journal, Vol.7, No.1/2/3/4, October 2020

customers tend to imitate the appearance of celebrities. It is necessary to minimize the negative effects of plastic surgery and reduce the wrong motives.

The Bayesian model is proposed by [15], which help to avoid the unforeseen consequences of plastic surgery in the health care system. The literature discusses the possibility for trade-offs between the clinical nature and other elements of customer service necessary to provide the service. It is noted that cosmetology clinics often do not provide the right balance between comfort and procedural possibilities. This is necessary to create loyalty and repeated calls for services. Wellness cosmetic centres have become a real force that affects health. As the interest in physical well-being increased, this type of therapy became popular among clients and medical specialists[16]. The centres of cosmetology treatment have become attractive for a growing number of clients. As a result of the development of various applications (treatment of diseases, improvement of appearance), cosmetology centres have become an integral part of the healthcare industry. Health tourism has started and has begun to thrive.

Aesthetic medicine has become one of the fastest growing segments of health tourism[17]. To date, however, scientific research on this market is clearly not enough. Services in the field of aesthetic medicine are usually only discussed descriptively, as a subcategory of medical tourism. It is noted that the quality of cosmetology services, the organizational characteristics of the cosmetology facilities, the relationship with specialists and service personnel, has a strong influence on the assessments of consumers, especially for the elderly [18]. However, there are no quantitative models for evaluation cosmologic services by consumers of aesthetic medicine. Interesting is the comparative analysis of health tourism in Asian countries, in particular, wellness services[19]. This market is globalized and competition is intensifying, which requires higher standards of service and uniqueness.

It shows thata dynamic market for a cosmetology establishment, a unique profile is needed that combines directly cosmetology services with other various accompanying service products and various similar offers[20]. Modern cosmetology centres offer clients an increasing number of services. They are very diverse, and include a variety of medicines, cosmetic specialists, aesthetics and hairdressing procedures, offered to clients as samples of products, profiled specialized medical and preventive packages of services, various health programs [21]. An trend in recent years is that more and more often different organizations realize the importance of organizing measures to improve the health of their employees, including using wellness and cosmetology procedures. There is a growing awareness of the need for health programs in general, as a means leading to the creation of a culture of health in organizations. The notion of a culture of health is becoming increasingly important for companies. Statistics show that the number of health problems is steadily increasing [22].

Resolving the cost issues, many companies have begun to implement health programs to improve the psycho-physical health of their employees. In particular, studies confirm the usefulness (in certain cases) of health-improving cosmetology programs in the process of forming a corporate culture of health[23]. There are factors that limit the usability of such program. It is necessary to note the problems of the safety of services and protection of patients' personal data, these services received. All formal and technical rules that directly or indirectly affect safety standards in cosmetological health centres determine the overall safety of cosmetology services[24]. Its level is an important competitive advantage in running a business, security is becoming increasingly important in marketing a health-oriented business. Because of the specifics of cosmetology services, there are 
Advanced Computational Intelligence: An International Journal, Vol.7, No.1/2/3/4, October 2020

many different segments of such security. Among them are medical aspects as well as personal information security. It is the last element that allows customers to trust a certain beauty establishment. Only careful protection of personal information ensures the ethics and confidentiality of the provision of cosmetology services, which is extremely important for their recipient. The problem of transparency in the market of cosmetology services in the context of official rules has not been solved in general [25]. This refers to the standards of services provided (not covering some relatively new forms of cosmetology services), the interrelationships of different quality components and specific service providers.

\subsection{Comparison Between Cosmetology Services}

Table 1.The composition of criteria for the assessment of cosmetology institutions (points)

\begin{tabular}{|c|c|c|}
\hline Internet communications and features & Services and prices & Personnel and equipment \\
\hline Online Consultant (1) & Services prea dth of (2) & Premises (2) \\
\hline Online Registration (1) & Prices level (2) & Specialists number (2) \\
\hline Online question(1) & Working time (2) & Personnel qualification(2) \\
\hline Call back (1) & Work on weekends (1) & Equipment level (2) \\
\hline Overall website quality (2) & Additional services (2) & The term of work in the market (2) \\
\hline Information, prices (2) & Services information(2) & \multirow[t]{8}{*}{ Exclusive services (1) } \\
\hline Information, discounts (2) & Location(2) & \\
\hline Social networks (2) & \multirow[t]{6}{*}{ Transport accessibility (2) } & \\
\hline Blogs (1) & & \\
\hline Comments, website(2) & & \\
\hline Comments, media (1) & & \\
\hline Photo, video materials (2) & & \\
\hline Online payment (1) & & \\
\hline
\end{tabular}

A meticulous service comparative has been made among difference cosmetology service providers particular in Asian countries. Further, the work of these cosmetic institutions was studied in more detail, relying on field observations with direct visits to institutions, accessible information on their websites and feedback from visitors in social networks and the Internet as a whole. The shrewd criteria has been set up and falls into three large groups [26]. Each of the contains its own set of sub criteria, the implementation of which is proposed to be assessed with the corresponding scores, shown in Table 1. 
Advanced Computational Intelligence: An International Journal, Vol.7, No.1/2/3/4, October 2020

Table 2.Evaluation of services and prices

\begin{tabular}{|c|c|c|c|c|c|c|c|c|c|c|c|c|c|}
\hline & 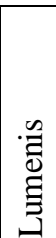 & 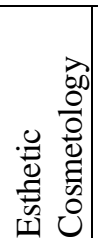 & 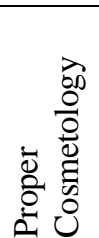 & 菾 & 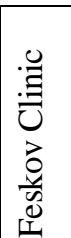 & 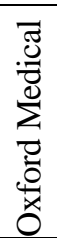 & 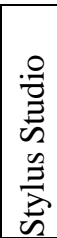 & 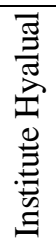 & 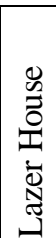 & 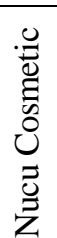 & 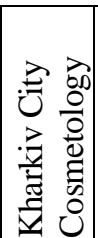 & 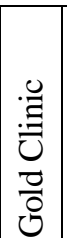 & 党 \\
\hline Services breadth (2) & 0 & \begin{tabular}{l|l}
0 \\
\end{tabular} & 1 & 2 & 2 & 1 & 0 & 0 & 0 & 1 & \begin{tabular}{|l|l|}
2 &
\end{tabular} & 2 & 1 \\
\hline Prices level (2) & 0 & 1 & 0 & 0 & 1 & 1 & 1 & 1 & 0 & 1 & 2 & 2 & 0 \\
\hline Working time (2) & 2 & 0 & 1 & 0 & 0 & 1 & 1 & 2 & 2 & 2 & 1 & 0 & 0 \\
\hline $\begin{array}{l}\text { Work on weekends } \\
\text { (1) }\end{array}$ & 1 & 0 & 1 & 0 & 0 & 0 & 1 & 1 & 1 & 0 & 0 & 0 & 0 \\
\hline $\begin{array}{l}\text { Additional services } \\
\text { (2) }\end{array}$ & 2 & 0 & 1 & 1 & 0 & 0 & 0 & 0 & 0 & 0 & 0 & 1 & 0 \\
\hline $\begin{array}{l}\text { Information about } \\
\text { services (2) }\end{array}$ & 1 & 0 & 2 & 1 & 1 & 1 & 2 & 2 & 2 & 1 & 2 & 2 & 1 \\
\hline Location (2) & 2 & 2 & 2 & 2 & 1 & 2 & 2 & 0 & 2 & 2 & 0 & 0 & 0 \\
\hline $\begin{array}{l}\text { Transport } \\
\text { accessibility (2) }\end{array}$ & 2 & 2 & 2 & 2 & 2 & 2 & 1 & 0 & 2 & 2 & 0 & 0 & 1 \\
\hline
\end{tabular}

Setting this criterion, an evaluation results of the most common cosmetology institutions in the Asian countries was carried out. These result shows (Table $2 \& 3$ ) that there can be additional, exclusive, unique opportunities (offers, services, procedures) that are not of a mass character, provided by only one cosmetology clinic but at this stage of the preliminary comparison, they should not be taken into account, since clients of such services find them not through a simple comparison and choice in the market of cosmetology services, but in other, specific ways.

Table 4.Evaluation of personnel and equipment

\begin{tabular}{|c|c|c|c|c|c|c|c|c|c|c|c|c|c|}
\hline & 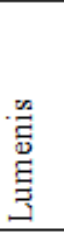 & 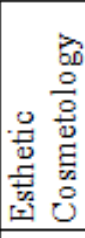 & 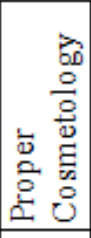 & 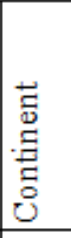 & 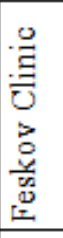 & 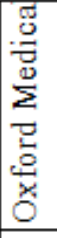 & 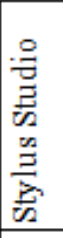 & 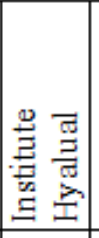 & 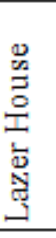 & 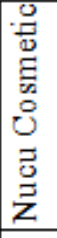 & 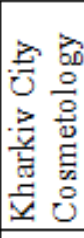 & 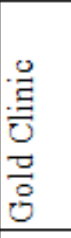 & 吝 \\
\hline Premises (2) & 1 & 0 & 2 & 2 & 2 & 1 & 1 & \begin{tabular}{|l|}
0 \\
\end{tabular} & 1 & 1 & 0 & 0 & 0 \\
\hline $\begin{array}{l}\text { Specialists number of } \\
\text { (2) }\end{array}$ & 1 & 0 & 1 & 1 & 1 & 2 & 0 & 1 & 2 & 2 & 2 & 2 & 0 \\
\hline $\begin{array}{l}\text { Personnel qualification } \\
\text { (2) }\end{array}$ & 0 & 2 & 2 & 1 & 1 & 1 & 2 & 1 & 2 & 2 & 2 & 1 & 1 \\
\hline Equipment level (2) & 2 & 0 & 2 & 1 & 0 & 0 & 2 & 0 & 2 & 2 & 1 & 1 & 1 \\
\hline $\begin{array}{l}\text { Work term at the market } \\
\text { (2) }\end{array}$ & 2 & 2 & 1 & 2 & 0 & 2 & 2 & 1 & 0 & 1 & 2 & 0 & 0 \\
\hline Exclusive services (1) & 0 & 0 & 1 & 1 & 0 & 0 & 0 & 1 & 0 & 0 & 0 & 1 & 1 \\
\hline
\end{tabular}


Advanced Computational Intelligence: An International Journal, Vol.7, No.1/2/3/4, October 2020

\section{Proposed FUZzY BASED FTMCP PARAdigm}

In order to strengthen the cosmetology services, we proposed a fuzzy based model having series of application decisions. Establishing theoretical and methodological foundations, we are using a Fuzzy Tech[27], specialized tool and taking numerical data from aforementioned table as a input elements which further generalized as communications (the sum of the assessment for individual sub-criteria may range from 0 to 19 points; their verbal estimates - weak, average, excellent), Services Prices (range from 0 to 15 points; their verbal estimates - low, medium, high), Staff Equipment (range from 0 to 11 points; their verbal estimates - bad, satisfactory, good). In Accordance to the required algorithm for this model, we represents each of the parameters in the form of linguistic variable [28], with three terms.

These can be represented graphically by the corresponding piecewise-linear membership functions[29]. Similarly, the output parameter will be obtained on a five-point scale: Estimation (range from 0 to 5 points; their verbal estimates - negative, zero, positive. Specific numerical parameters for constructing the input and output membership functions described above are presented in Table 5.The proposed FTMCP model is shown in Figure 1. In addition to the input variables (represented by the membership functions), the model contains a set of decision estimations[3]. It is a complete search of variants of combinations of all possible linguistic terms and a corresponding conclusion on the evaluation. In this case, there are more than 10 Possible estimations. The Figure 2, renders the applied values in Fuzzy Tech application to get the real time results from applied communications, services and the Staff Equipment. Figure 3, depicts the estimated ratio of these terms according to the increasing number of cosmetology institutions. These factors clearly depict the dependence of the results on the input data. It's possible to establish areas of strong influence of a sharp change in an individual input parameter on a generalized estimate.

Table 5. Numerical values for the membership functions of input and output variables

\begin{tabular}{|c|c|c|c|c|c|c|}
\hline Variable & Term & level 0 & $\begin{array}{c}\text { Increase from } 0 \\
\text { to } 1\end{array}$ & level 1 & $\begin{array}{l}\text { Decrease } \\
\text { from } 1 \text { to } 0\end{array}$ & level 0 \\
\hline \multirow{3}{*}{ 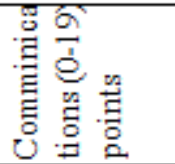 } & Weak & - & - & - & $0-8$ & $8-19$ \\
\hline & Average & $0-4$ & $4-10$ & 10 & $10-17$ & $17-19$ \\
\hline & Excellent & $0-12$ & $12-19$ & 19 & - & - \\
\hline \multirow{3}{*}{ 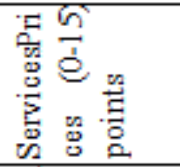 } & Low & - & - & - & $0-7$ & $7-15$ \\
\hline & Medium & $0-3$ & $3-8$ & 8 & $8-14$ & $14-15$ \\
\hline & High & $0-8$ & $8-15$ & 15 & - & - \\
\hline \multirow{5}{*}{ 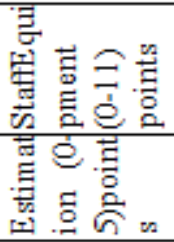 } & Bad & - & - & - & $0-5$ & $5-11$ \\
\hline & Satisfactory & $0-4$ & $1-4$ & $4-7$ & $7-10$ & $10-11$ \\
\hline & Good & $0-6$ & $6-11$ & 11 & - & - \\
\hline & Negative & - & - & $0-0.5$ & $0.5-2.5$ & $2.5-5$ \\
\hline & Zero & $0-0.5$ & $0.5-2$ & $2-3$ & $3-4.5$ & $4.4-5$ \\
\hline
\end{tabular}

The statistics illustrated in figure 3, presages the variations in outcome. This is due to the market situation. As number of cosmetology centre increases from 30 to 60, the significant improvements have been recorded to communicating the consumers. Thereby, number of services are also increased but staff members are in same number. 
Advanced Computational Intelligence: An International Journal, Vol.7, No.1/2/3/4, October 2020
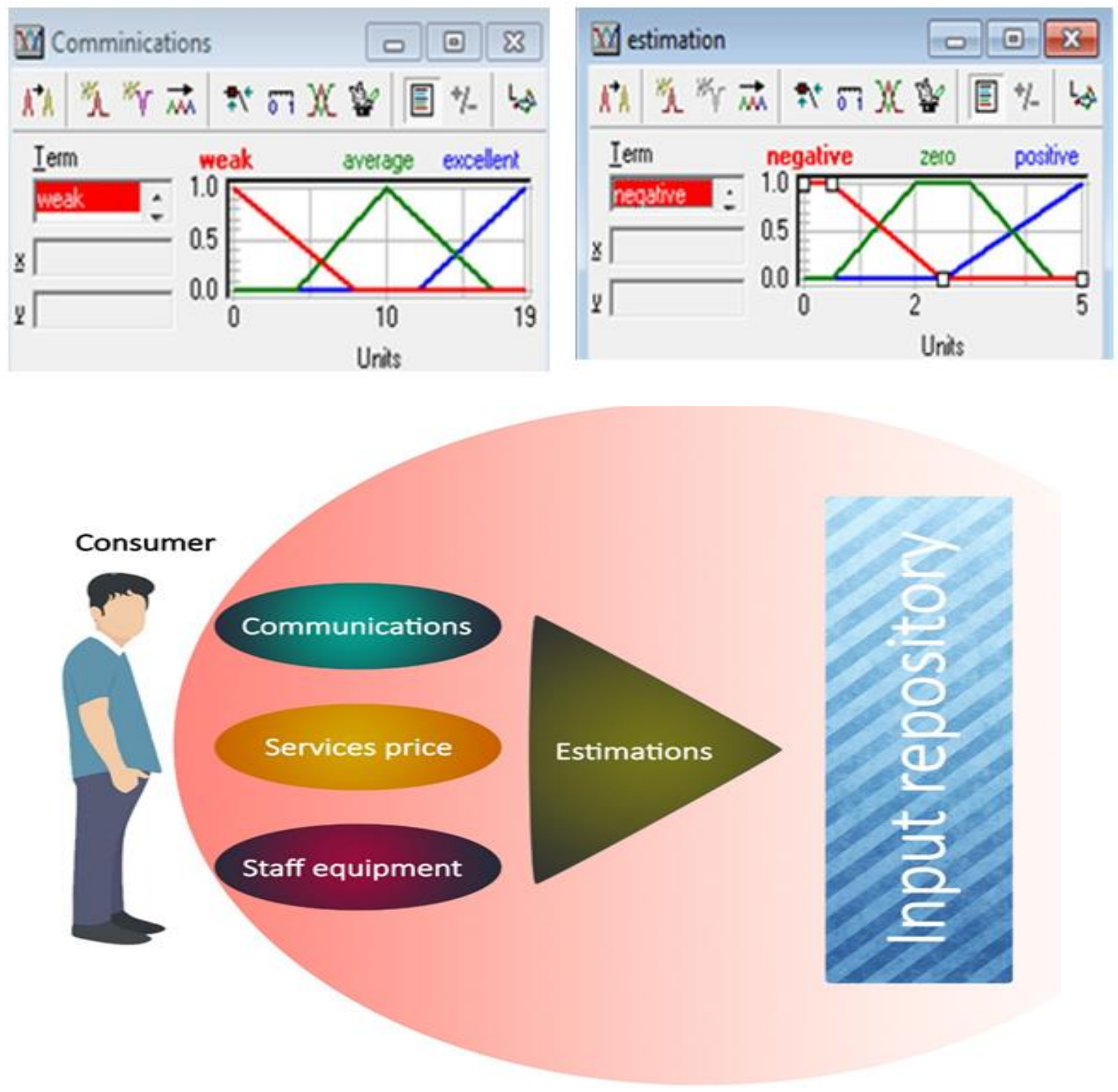

Figure 1. Proposed FTMCP model 
(a)

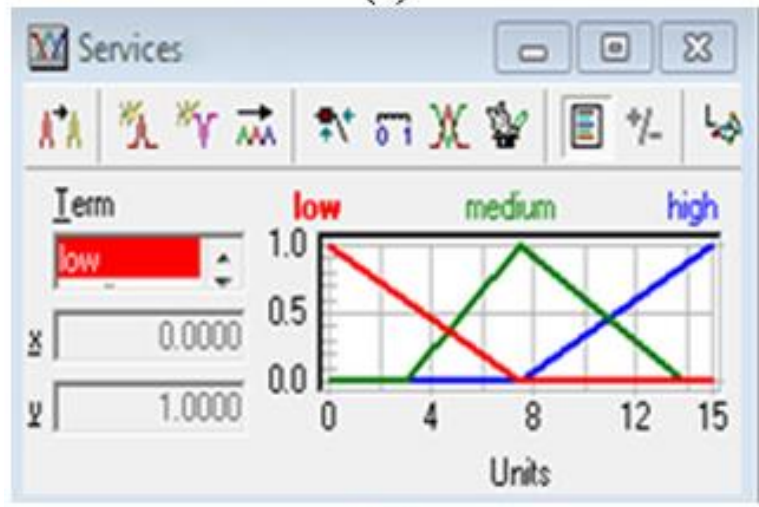

(b)

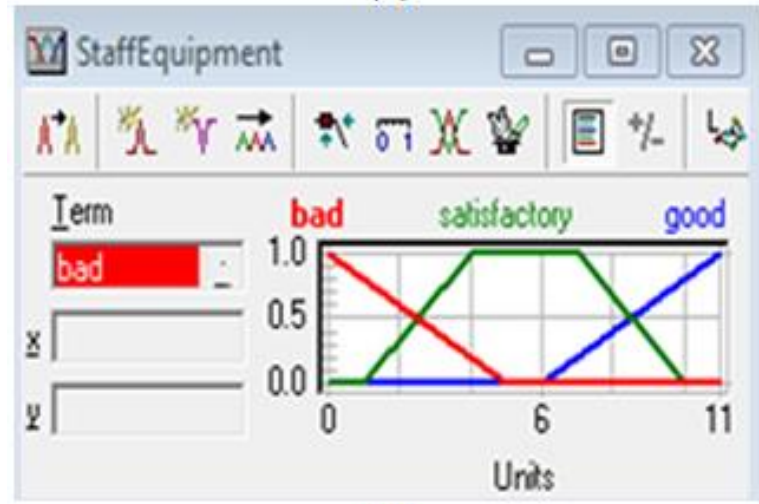

(c) (d)

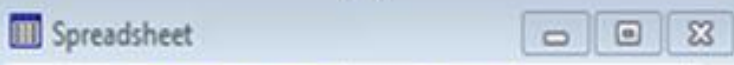

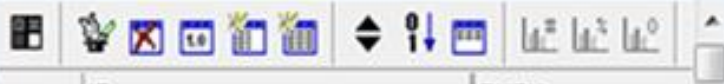

IF THEN

* ComminicatiServicesPrix StalfEqupr DOS estimation

\begin{tabular}{|c|c|c|c|c|c|}
\hline 1 & weak & low & bad & 1.00 & negative \\
\hline 2 & weak & low & satisfactory & 1.00 & negative \\
\hline 3 & weak & low & good & 1.00 & negative \\
\hline 4 & weak & mediun & bad & 1.00 & negative \\
\hline 5 & weak & medium & satisfactory & 1.00 & negative \\
\hline 6 & weak & medum & good & 1.00 & zero \\
\hline 7 & weak & high & bad & 1.00 & zero \\
\hline 8 & weak & high & satisfactory & 1.00 & zero \\
\hline 9 & weak & high & good & 1.00 & zero \\
\hline 10 & average & low & bad & 1.00 & negative \\
\hline 11 & average & low & satisfactory & 1.00 & negative \\
\hline 12 & average & low & good & 1.00 & zero \\
\hline 13 & average & medum & bad & 1.00 & negative \\
\hline 14 & average & mediun & satisfactory & 1.00 & zero \\
\hline 15 & average & mediun & good & 1.00 & zero \\
\hline 16 & average & high & bad & 1.00 & zero \\
\hline
\end{tabular}

(d)

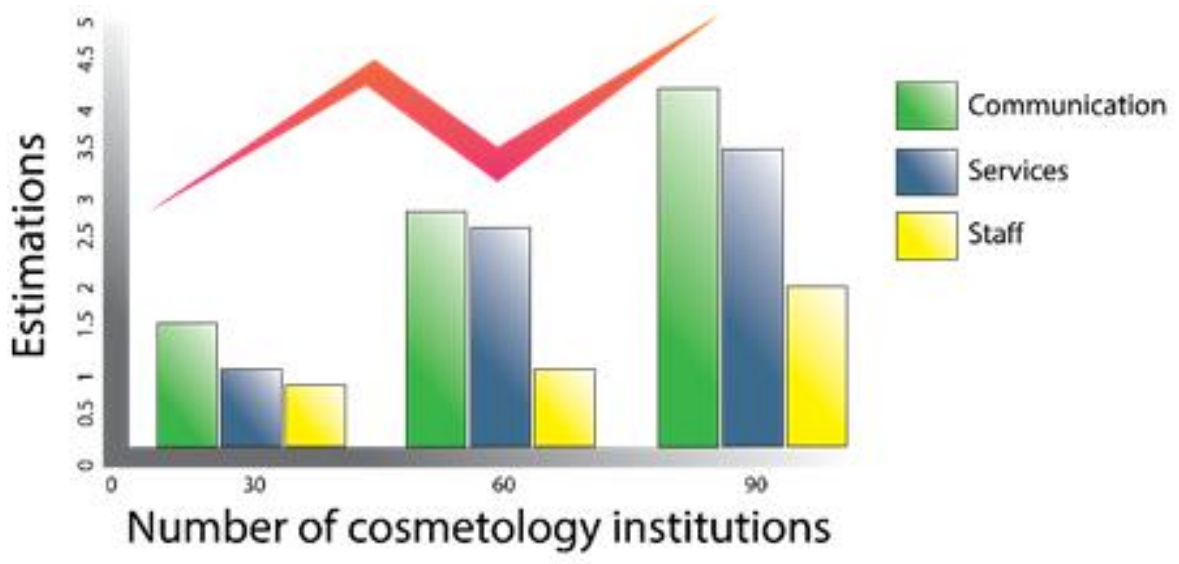

Figure 3. The trend estimation results 
Advanced Computational Intelligence: An International Journal, Vol.7, No.1/2/3/4, October 2020

Table 6.List of intended cosmetology institute with assessments points

\begin{tabular}{|l|l|}
\hline \multicolumn{1}{|c|}{ Name } & Scores \\
\hline Cosmetology institute 1 & 3,6 \\
\hline Cosmetology institute 2 & 3,4 \\
\hline Cosmetology institute 3 & 3,1 \\
\hline Cosmetology institute 4 & 2,8 \\
\hline Cosmetology institute 5 & 2,7 \\
\hline Cosmetology institute 6 & 2,3 \\
\hline Cosmetology institute 7 & 2,3 \\
\hline Cosmetology institute 8 & 2,1 \\
\hline Cosmetology institute 9 & 2,0 \\
\hline Cosmetology institute 10 & 2,0 \\
\hline Cosmetology institute 11 & 1,7 \\
\hline Cosmetology institute 12 & 0,3 \\
\hline Cosmetology institute 13 & 0,3 \\
\hline
\end{tabular}

\subsection{FTMCP Assessment Process}

The proposed FTMCP model makes the assessment on the basis of the given shrewd parameters. These parameters are divided into three main groups. For example, the input of initial data and obtaining the results. The obtained numerical results of calculations for all the cosmetological institutions selected for consideration are given in Table 6. The table shows the distribution into four main groups: leaders in the market of cosmetology services. The numerical passement is shown in Figure 4, that ratifies some drawbacks from consumer point of view due to high prices, insufficient comprehensive list of services, and the lack of substantial communication. At the same instance, no one is using new, modern marketing communications capabilities (for example, QR codes for mobile devices, special versions of smart phone websites, electronic payment through bank cards). A common drawback is also a weak reflection of customer feedback[30]. In particular, the review gives the impression of artificial, false, irrelevant, do not inspire confidence because of the lack of specifics, time-binding and the like. 
Advanced Computational Intelligence: An International Journal, Vol.7, No.1/2/3/4, October 2020

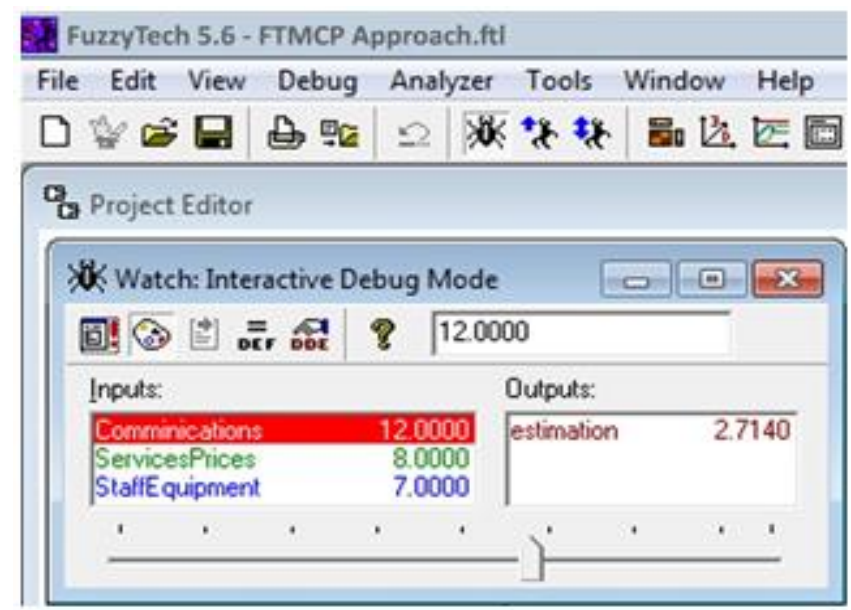

Figure 4. The FTMCP parameter adjustment

\section{Conclusion}

Every person ambitious to avail good healthcare facilities at affordable price. The choice of appropriate healthcare and related institute is remained a critical challenge. Keeping current situation, we have developed a Fuzzy based Cosmetology Paradigm (FTMCP) which renders the possible solution. This model can be used both to compare the cosmetic institutions that exist in the cosmetology services industry and to self-analyze the function of a different cosmetic institution. It allows to identify the strengths and weaknesses of own competitors. Corresponding actions to address the identified shortcomings may lead to an increase in the assessment of the institution by the public, patients, visitors, potential clients. In order to ratify the survey results we used Fuzzy Tech application that provides maximum estimated output.

Moreover, the proposed approach can be successfully used for a wide range of tasks of multi-criteria evaluation of the service, marketing components in the provision of various services by the relevant enterprises (and institutions) to the population. Such institutions include, in particular, pharmacies, medical institutions (in the context of the introduction of insurance medicine), other enterprises providing various servicing, domestic and commercial services.

\section{REFERENCES}

[1] K. A. Hafiz and K. A. M. Ali, "A Proposed Model of Purchase Decisions by Young Adults in Malaysia's Beauty, Health and Wellness Industry,” Int. J. Acad. Res. Bus. Soc. Sci., vol. 7, no. 4, p. Pages 10981115, Jun. 2017, doi: 10.6007/IJARBSS/v7-i4/2918.

[2] S. Ashraf, S. Saleem, A. H. Chohan, Z. Aslam, and A. Raza, "Challenging strategic trends in green supply chain management," Int. J. Res. Eng. Appl. Sci. JREAS, vol. 5, no. 2, pp. 71-74, 2020, doi: 10.46565/jreas.2020.v05i02.006.

[3] S. Ashraf, T. Ahmed, S. Saleem, and Z. Aslam, "Diverging Mysterious in Green Supply Chain Management," Orient. J. Comput. Sci. Technol., vol. 13, no. 1, pp. 22-28, May 2020, doi: 10.13005/ojcst13.01.02.

[4] S. Ashraf, T. Ahmed, A. Raza, and H. Naeem, "Design of Shrewd Underwater Routing Synergy Using Porous Energy Shells," Smart Cities, vol. 3, no. 1, pp. 74-92, Feb. 2020, doi: 10.3390/smartcities3010005. 
Advanced Computational Intelligence: An International Journal, Vol.7, No.1/2/3/4, October 2020

[5] S. Ashraf and T. Ahmed, "Dual-nature biometric recognition epitome," Trends Comput. Sci. Inf. Technol., vol. 5, no. 1, pp. 008-014, Jun. 2020, doi: 10.17352/tcsit.000012.

[6] S. Markovic, S. Raspor, and J. Komšic, "Service Quality Measurement in Croatian Wellness Tourism: An Application of the SERVQUAL Scale," Acad. Tur. - Tour. Innov. J., vol. 5, no. 1, pp. 47-58, 2012.

[7] S. Ashraf, A. Ahmad, A. Yahya, and T. Ahmed, "Underwater routing protocols: Analysis of link selection challenges," AIMS Electron. Electr. Eng., vol. 4, no. 3, pp. 234-248, 2020, doi: 10.3934/ElectrEng.2020.3.234.

[8] E. M. Ampaw, J. Chai, B. Liang, S.-B. Tsai, and J. Frempong, "Assessment on health care service quality and patients' satisfaction,” Kybernetes, Jan. 2020, doi: 10.1108/K-06-2019-0409.

[9] S. Ashraf, Z. A. Arfeen, M. A. Khan, and T. Ahmed, "SLM-OJ: Surrogate Learning Mechanism during Outbreak Juncture," Int. J. Mod. Trends Sci. Technol., vol. 6, no. 5, pp. 162-167, May 2020, doi: 10.46501/IJMTST060525.

[10] S. Ashraf, S. Saleem, T. Ahmed, Z. Aslam, and D. Muhammad, "Conversion of adverse data corpus to shrewd output using sampling metrics," Vis. Comput. Ind. Biomed. Art, vol. 3, no. 19, doi: 10.1186/s42492-020-00055-9.

[11] M. Memarpour, E. Hassannayebi, N. FattahiMiab, and A. Farjad, "Dynamic allocation of promotional budgets based on maximizing customer equity," Oper. Res., Aug. 2019, doi: 10.1007/s12351-019-005103.

[12] S. Ashraf, S. Saleem, and T. Ahmed, "Sagacious Communication Link Selection Mechanism for Underwater Wireless Sensors Network," Int. J. Wirel. Microw. Technol., vol. 10, no. 4, pp. 22-33, Aug. 2020, doi: 10.5815/ijwmt.2020.04.03.

[13] "EconPapers: Service Quality Measurement in Croatian Wellness Tourism: An Application of the SERVQUALScale." https://econpapers.repec.org/article/prpjattij/v_3a5_3ay_3a2012_3ai_3a1_3ap_3a4758.htm (accessed Jun. 06, 2020).

[14] S. Ashraf, A. Raza, Z. Aslam, H. Naeem, and T. Ahmed, "Underwater Resurrection Routing Synergy using Astucious Energy Pods,” J. Robot. Control JRC, vol. 1, no. 5, 2020, doi: 10.18196/jrc.1535.

[15] "Bayesian Model - an overview | ScienceDirect Topics." https://www.sciencedirect.com/topics/computerscience/bayesian-model (accessed Jun. 06, 2020).

[16] "The idea of beauty is always shifting. Today, it's more inclusive than ever." https://www.nationalgeographic.com/magazine/2020/02/beauty-today-celebrates-all-social-media-playsa-role-feature/ (accessed Aug. 09, 2020).

[17] "Clinical Evaluation of a Topical Formulation for the Management of Onychomycosis," JCAD | The Journal of Clinical and Aesthetic Dermatology, Jul. 01, 2020. https://jcadonline.com/mycoclearonychomycosis/ (accessed Aug. 09, 2020).

[18] S. Ashraf, D. Muhammad, M. Shuaeeb, and Z. Aslam, "Development of Shrewd Cosmetology Model Through Fuzzy Logic," J. Res. Eng. Appl. Sci., vol. 5, no. 3, pp. 93-99, Jul. 2020, doi: 10.46565/jreas.2020.v05i03.003.

[19] Z. Song and K. Baicker, "Effect of a Workplace Wellness Program on Employee Health and Economic Outcomes: A Randomized Clinical Trial," JAMA, vol. 321, no. 15, pp. 1491-1501, Apr. 2019, doi: 10.1001/jama.2019.3307.

[20] S. Ashraf and T. Ahmed, "Machine Learning Shrewd Approach For An Imbalanced Dataset Conversion Samples," J. Eng. Technol. JET, vol. 11, no. 1, Jun. 2020, Accessed: Jul. 05, 2020. [Online]. Available: https://journal.utem.edu.my/index.php/jet/article/view/5896.

[21] S. Ashraf, D. Muhammad, and Z. Aslam, "Analyzing challenging aspects of IPv6 over IPv4," J. Ilm. Tek. ElektroKomput. Dan Inform., vol. 6, no. 1, pp. 54-67, Jul. 2020, doi: 10.26555/jiteki.v6i1.17105.

[22] M. Nordentoft, "Follow up study of mortality among users of hostels for homeless people in Copenhagen," BMJ, vol. 327, no. 7406, pp. 81-0, Jul. 2003, doi: 10.1136/bmj.327.7406.81.

[23] R. Fabius, S. G. Frazee, D. Thayer, D. Kirshenbaum, and J. Reynolds, "The Correlation of a Corporate Culture of Health Assessment Score and Health Care Cost Trend," J. Occup. Environ. Med., vol. 60, no. 6, pp. 507-514, Jun. 2018, doi: 10.1097/JOM.0000000000001305.

[24] S. Ashraf, M. Gao, Z. Mingchen, T. Ahmed, A. Raza, and H. Naeem, "USPF: Underwater Shrewd Packet Flooding Mechanism through Surrogate Holding Time," Wirel. Commun. Mob. Comput., vol. 2020, pp. 1-12, Mar. 2020, doi: 10.1155/2020/9625974. 
Advanced Computational Intelligence: An International Journal, Vol.7, No.1/2/3/4, October 2020

[25] "Cosmetologists Penalties and Sanctions." https://www.tdlr.texas.gov/enforcement/cossanctions.htm (accessed Aug. 09, 2020).

[26] S. Ashraf, M. Gao, Z. Chen, S. Kamran, and Z. Raza, "Efficient Node Monitoring Mechanism in WSN using Contikimac Protocol," Int. J. Adv. Comput. Sci. Appl., vol. 8, no. 11, 2017, doi: 10.14569/IJACSA.2017.081152.

[27] "Fuzzy Tech." https://www.merlot.org/merlot/viewMaterial.htm?id=427879 (accessed Aug. 09, 2020).

[28] S. Ashraf, Z. Aslam, A. Yahya, and A. Tahir, "Underwater Routing Protocols Analysis of Intrepid Link Selection Mechanism, Challenges and Strategies," Int. J. Sci. Res. Comput. Sci. Eng., vol. 8, no. 2, pp. 19, Apr. 2020, doi: 10.26438/ijsrcse/v8i2.19.

[29] L. Coroianu, M. Gagolewski, and P. Grzegorzewski, "Piecewise linear approximation of fuzzy numbers: algorithms, arithmetic operations and stability of characteristics," Soft Comput., vol. 23, no. 19, pp. 9491-9505, Oct. 2019, doi: 10.1007/s00500-019-03800-2.

[30] L. Willott, "Customer Service Stats," Customer Thermometer, Nov. 25, 2019. https://www.customerthermometer.com/customer-service/customer-service-and-satisfaction-statistics-for2020/ (accessed Aug. 09, 2020).

\section{AUTHORS}

SHAHZAD ASHRAF received B.E. degree in Computer Systems Engineering, and M.E. in Communication System and Networks from Mehran Engineering \& Technology University, Jamshoro Pakistan in 2004, and 2014 respectively. He got Ph.D. degree in Information and Communication Engineering with the College of Internet of Things of Engineering, Hohai University Changzhou China in 2018. From 2005 to 2016, he served as an Assistant Professor at NFC Institute of Engineering and Technology Multan, Pakistan. His area of interest includes computer engineering, wireless communication, robotics and control, signal processing, grid and distributed computing, computer hardware and networks, vector graphics designing, artificial intelligence, machine learning, neuro-fuzzy systems, computer architecture, solid state devices, and web engineering.

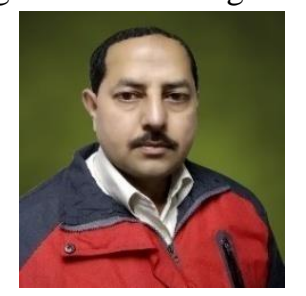

$\mathrm{He}$ is an active and prominent reviewer of many renowned international journals including IEEE Access, ACM, wireless personal communications, IET, IETE, international journal of distributed sensor networks, international journal of microwave and wireless technologies, journal of robotics and control, international journal of data science and analytics, international journal of computers \& technology, Technium: romanian journal of applied sciences and technology, iran journal of computer science, international arab journal of information technology, emerald: sensor review, international journal of pervasive computing and communications, journal of engineering and technology, i manager: journal on wireless communication networks, international journal of advanced research in computer and communication engineering, advances in science, technology and engineering systems journal, and IGI global.

SEHRISH SALEEM did her Bachelor Science in Computer Science degree from NFC Institute of Engineering and Technology Multan and MPhil in Computer Science from National College of Business Administration \& Economics Lahore Pakistan in 2013 and 2016, respectively. She is serving as a Lecturer in Department of Computer Science at Muhammad Nawaz Sharif University of Engineering \& Technology Multan Pakistan. She focused on Software Engineering during her thesis work in MPhil CS. Her research interest includes Big Data Analytics, distributed Computing, Artificial Intelligence and machine learning.

SYED AFNAN received B.S. degree in Computer Sciences from University of Karachi, Karachi Pakistan in the year 2006. He completed his M.S. in Computer and Communication Networks from Hamdard University, Karachi Pakistan in 2020. He is
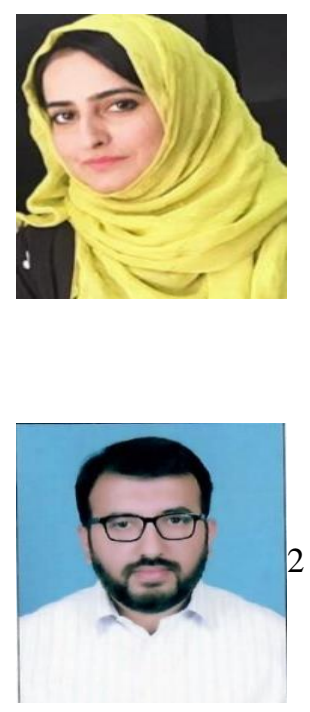
Advanced Computational Intelligence: An International Journal, Vol.7, No.1/2/3/4, October 2020

currently enrolled in M.Phil. leading to Ph.D. program at Hamdard University, Karachi Pakistan. He is currently working at Hilal Foods (Pvt.) Limited, Pakistan as Head of IT Infrastructure. He also served Dow University of Health Sciences, Karachi Pakistan on different positions including Director IT, Head of IT Governance and System Administrator from year 2010 to 2019. His area of interest includes system analysis and design, cryptography, inter-communication networks, wireless communication, network security, system architecture and design, machine learning, deep learning, neural and fuzzy system, and Internet of things. 